\title{
O direito à cidade e mobilidade social:um estudo sobre os trilhos que cortam uma cidade
}

\section{The right to the city and social mobility: a study on the trails that cut through a city}

\author{
Rosemeri da Silva Paixão \\ Doutoranda do Programa de Pós-Graduação em Humanidades Culturas e Artes \\ (PPGHCA), Universidade do Grande Rio (UNIGRANRIO) \\ rosemeri.paixao@unigranrio.edu.br \\ orcid.org/0000-0001-8909-7264
}

\author{
Rosane Cristina de Oliveira \\ Programa de Pós-Graduação em Humanidades Culturas e Artes (PPGHCA), \\ Universidade do Grande Rio (UNIGRANRIO) \\ rosanecrj@unigranrio.edu.br \\ orcid.org/0000-0003-1286-5792

\section{Jacqueline de Cassia Pinheiro Lima} \\ Programa de Pós-Graduação em Humanidades Culturas e Artes (PPGHCA), \\ Universidade do Grande Rio (UNIGRANRIO) \\ jpinheiro@unigranrio.edu.br \\ orcid.org/0000-0003-0153-8948
}

Resumo.Este artigo tem como principal objetivo discutir a questão do direito à cidade, especificamente em relação ao direito de ir e vir, tendo como objeto de estudo o processo de urbanização e o impacto promovido pela construção da linha férrea na região do município de Duque de Caxias da Baixada Fluminense do Estado do Rio de Janeiro. Neste estudo, apresentamos o resultado de pesquisa realizada com 52 voluntários anônimos, moradores das regiões de fronteira com a linha férrea no município caxiense, através da plataforma Google Formulários. $\mathrm{O}$ formulário foi distribuído nas redes sociais, indagando sobre as vantagens e desvantagens em morar nas proximidades da ferrovia. 
Palavras-Chave: Mobilidade Urbana. Direito à Cidade. Baixada Fluminense.

\begin{abstract}
This article has as main objective to discuss the issue of the right to the city, specifically in relation to the right to come and go, having as object of study the urbanization process and the impact promoted by the construction of the railway in the region of the municipality of Duque de Caxias the Baixada Fluminense of the State of Rio de Janeiro. In this study, we present the result of a research carried out with 52 anonymous volunteers, living in the regions bordering the railway line in the city of Caxiense, through the Google Forms platform. The form was distributed on social networks, asking about the advantages and disadvantages of living close to the railroad.
\end{abstract}

Keywords: Urban Mobility. Right to the City. Baixada Fluminense.

Recebido: 01/10/2017 Aceito: 27/10/10 Publicado: 06/11/2017

\title{
1. Introdução
}

O direito de ir e vir é constitucional e na formação urbana de uma cidade há a necessidade de se pensar em como a população, especialmente nos centros urbanos, se locomovem cotidianamente. Pensar em um meio de transporte público coletivo eficiente e de qualidade é uma das obrigações daqueles que estão gerindo uma Cidade ou um Estado. Neste sentido, refletir como este meio de transporte pode interferir na vida das pessoas que moram próximas às vias férreas é uma questão fundamental no que concerne a sociabilidade e o impacto econômico que atinge a população.

O trem como meio de transporte terrestre, seja ele de transporte público coletivo ou de transporte urbano de cargas, em geral é o mais rápido quando comparado com as rodovias dos grandes centros urbanos, como é o caso do Rio de Janeiro. Nas vias férreas não observamos, comumente, os mesmos problemas das rodovias, como engarrafamentos por excesso de veículos, fechamento parcial ou total por causa de acidentes, dificuldade em procurar novas rotas para chegar ao destino desejado, entre outros. O impacto ambiental também é um fator diferencial entre o transporte ferroviário e o rodoviário, uma vez que carros, caminhões, ônibus poluem mais em decorrência da queima dos combustíveis utilizados por estes veículos. Segundo Vasconcellos (2013, p. 2) "o transporte coletivo consome menos energia e emitem menos poluentes que as viagens de transporte individual. $\mathrm{O}$ custo médio por habitante das viagens no transporte coletivo é muito inferior ao custo da viagem no transporte individual". 
Neste estudo, chamamos a atenção para o transporte ferroviário e sua importância para a mobilidade urbana, destacando os trilhos que cortam o município de Duque de Caxias, situado na região da Baixada Fluminense do Estado do Rio de Janeiro. É importante salientar o aspecto da formação urbana a partir da construção de sociabilidade e relações econômicas ao longo das ferrovias, uma vez que no meio urbano os trilhos perpassam por inúmeros bairros e, dessa forma, é comum uma série de transformações de ordem social e econômica ao longo destas vias.

Do ponto de vista metodológico, além do caráter exploratório e descritivo, apresentamos, brevemente, os resultados a partir da aplicação de questionários através do Google Formulários e distribuída nas redes sociais, que analisou a opinião de 52 voluntários, anônimos, sobre as vantagens e os incômodos em morar próximo a ferrovia e as estações do município de Duque de Caxias.

\section{Direito à cidade, interdisciplinaridade e mobilidade}

Os estudos acerca do direito à cidade pautam-se, na perspectiva interdisciplinar, no esforço de abordagem advindas de múltiplas áreas do conhecimento, como a antropologia, sociologia urbana, história social, planejamento urbano, administração, entre outras. Para Japiassu (1976), um estudo interdisciplinar pode ser reconhecido a partir da realização de estudos que incorporem várias especialidades, uso de metodologias e conceitos de diversas disciplinas,

\footnotetext{
"a fim de fazê-los integrarem e convergirem, depois de terem sido comparados e julgados. Donde podermos dizer que o papel específico da atividade interdisciplinar consiste, primordialmente, em lançar uma ponte para ligar as fronteiras que haviam sido estabelecidas anteriormente entre as disciplinas com o objetivo preciso de assegurar a um seu caráter propriamente positivo, segundo modos particulares e com resultados específicos". (Autor, 1976, p. 75)
}

Além da definição apresentada por Japiassu, Olga Pombo (2005), enfatiza que a interdisciplinaridade ocorre para além do diálogo entre áreas de conhecimento. Para a autora, o processo de pesquisa e elaboração de análises interdisciplinares acontece a partir da construção do conhecimento científico a partir do entrelaçamento desafiador entre várias disciplinas, cujo resultado apresenta-se advindo de múltiplos olhares e diversas possibilidades.

As discussões conceituais em torno do Direito à Cidade, questão urbana e mobilidade urbana são fundamentais. Neste estudo destacamos David Harvey no livro "Cidades rebeldes: do direito à cidade à revolução urbana" e Henri Lefebvre com o livro "O direito à cidade", onde os autores proporcionam um debate crítico sobre a urbanização. Harvey (2014), ao dialogar com conceituação de Lefebvre (2001) sobre o direito à cidade, argumenta que a cidade que se quer é resultado do entrelaçamento das relações sociais, "com a natureza, estilos de vida, tecnologias e valores estéticos". Neste sentido, o direito à cidade diz respeito à supremacia do direito comum, do poder coletivo e, dessa forma, os direitos individuais estariam em segundo plano. Portanto, para Harvey 
(2014, p.2), "é um direito comum antes de individual já que esta transformação depende inevitavelmente do exercício de um poder coletivo de moldar o processo de urbanização. A liberdade de construir e reconstruir a cidade e a nós mesmos é, como procuro argumentar, um dos mais preciosos e negligenciados direitos humanos".

A questão do "direito de ir e vir" em relação as vias férreas, faz parte de algumas abordagens de Jacobs (2011), em "Morte e Vida nas Grandes Cidades", mais especificamente no capítulo intitulado "A maldição das zonas de fronteira desertas". Neste estudo, a autora apresenta uma discussão importante para este artigo, pois relata como as zonas de fronteiras criam bairros decadentes e que a linha férrea é um exemplo clássico de fronteira. Segundo Jacobs (2011, p. 285) "as linhas férreas são um exemplo clássico de fronteiras, tanto que passam a significar, há muito tempo, também fronteiras sociais - 'do lado da linha do trem'” e é possível ver estas diferenças em alguns bairros "cortados" pelos trilhos.

Entre os estudos acerca da Cidade de Duque de Caxias, destacamos Souza (2014) e Lacerda (2001 e 2003), pesquisadores sobre a história da Baixada Fluminense e especificadamente a Cidade de Duque de Caxias. Auxiliando a pesquisa sobre a formação da estrada de ferro no Rio de Janeiro, o autor Rodriguez (2004), traz fatores históricos importantes para a construção da memória em relação aos transportes ferroviários no Estado do Rio de Janeiro. Outro referencial importante sobre a história da Baixada Fluminense é a Revista Pilares da História, que enfatiza artigos sobre a História de Duque de Caxias e da Baixada Fluminense com divulgação conjunta do Instituto Histórico da Câmara Municipal de Duque de Caxias e a Associação dos Amigos do Instituto Histórico.

\section{Os trilhos que cortam a cidade caxiense}

As ferrovias, em geral, apresentam problemas estruturais, oriundos de políticas públicas para a área de transportes que não foram bem institucionalizadas. Um bom exemplo são alguns ramais ferroviários destinados à Baixada Fluminense. Nesta localidade, ao longo de sua história, houve uma perda considerável de sua extensão quando se compara às últimas décadas do século XX, com trechos ferroviários abandonados, terminais e estações destruídos. Estas informações fazem parte dos acervos e demais pesquisas realizadas pela Sociedade de Pesquisa para Memória do Trem.

Foi realizada uma pesquisa, através do Google Formulário, no primeiro semestre de 2017, com 52 participantes, voluntários e anônimos. O objetivo principal foi compreender a formação do município de Duque de Caxias junto a ferrovia que perpassa por três distritos do município (Caxias, Campos Elíseos e Imbariê) e analisar o comportamento das pessoas que moram em torno da via férrea e como estas pessoas se adaptaram a sua travessia para que possam se locomover para estes dois lados da linha férrea utilizado as passarelas, passagens de nível etc.

Dos 52 participantes da pesquisa, $54 \%$ são do sexo masculino e $46 \%$ do sexo feminino; $79 \%$ tem idade entre 25 a 59 anos, $19 \%$ entre 16 e 24 anos e $2 \%$ entre 60 anos ou mais; 
$46 \%$ com ensino superior, $52 \%$ com ensino médio e $2 \%$ com ensino fundamental; e faixa salarial: $56 \%$ de 1 a 2 salários mínimos, $29 \%$ entre 3 a 4 salários mínimos; 4\% entre 5 a 6 salários mínimos e $11 \%$ acima de 6 salário mínimos.

Os participantes da pesquisa são moradores próximos as estações de trem do município de Duque de Caxias: 10\% em Duque de Caxias; $11 \%$ em Corte 8; 15\% em Gramacho; 6\% em Campos Elíseos; 31\% em Jardim Primavera; 19\% em Saracuruna; 4\% em Imbariê com 4\%; 2\% em Manoel Belo e 2\% em Parada Angélica. Não houveram voluntários moradores próximo à estação Morabi. A proximidade das residências dos participantes, perante a ferrovia foi: $0 \mathrm{~m}$ a $50 \mathrm{~m}: 12 \% ; 50 \mathrm{~m}$ a $120 \mathrm{~m}: 21 \% ; 120 \mathrm{~m}$ a $300 \mathrm{~m}$ : $21 \%$ e $300 \mathrm{~m}$ ou mais: $46 \%$.

As vantagens sobre morar próximo a ferrovia, $67 \%$ das pessoas responderam que é vantajoso morar próximo a ferrovia, mas apenas $21 \%$ das pessoas dizem ser mais vantajoso se for próximo as estações de trem, mas 52\% das pessoas acreditam que o bairro não fica mais valorizado por causa da ferrovia e $67 \%$ das pessoas acham que não há áreas de lazer em torno da ferrovia e 50\% pessoas apontam que não há comércio em torno da ferrovia. Uma questão interessante abordada diz respeito às áreas de lazer e o comércio no entorno da ferrovia: apenas $10 \%$ dos que responderam o questionário declararam ser moradores próximos da estação de Duque de Caxias (o "centro de Duque de Caxias"), pois esta área possui mais espaços de lazer e comércio e o principal ponto de deslocamento para outras áreas do município caxiense.

Sobre a ferrovia ser ponto de referência para a residência, $52 \%$ das pessoas que moram mais próximos da ferrovia, responderam que sim, mas os $48 \%$ que moram mais longe da ferrovia, disseram que não, a ferrovia não é ponto de referência para a residência. $E$ isso poderia ser visto como uma vantagem de quem mora próximo a ferrovia e as estações, já que as mesmas podem servir de orientação para encontrar os endereços.

Áreas de lazer, próximas a ferrovia e que são mais frequentadas são: praças: 58\%; feiras livres: 52\%; bares: $46 \%$; teatros: $29 \%$; escola de samba/bloco de carnaval e bibliotecas: 14\%; clubes sociais: $10 \%$; áreas esportivas: $6 \%$; feiras temáticas: 4\%. Já circos, parques de diversão, shoppings e cinema representaram apenas $2 \%$ de lugares frequentados pelos voluntários que responderam à pesquisa.

A mobilidade de travessia de um lado ao outro é uma questão controversa, pois em diversos pontos da via férrea (que depende de passarelas, viadutos, passagem de nível e clandestinas (são abertos buracos entre os muros da via férrea), são travessias perigosas, com iluminação precária ou nenhuma iluminação, lixo e mato alto onde a população se obriga a correr riscos de assalto e estupro. Alguns assassinatos já ocorreram nas vias férreas da cidade, devido à falta de segurança do local, com pessoas assassinadas de diversas formas, até mesmo jogadas vivas na linha férrea para que o trem as mutilasse. A cidade de Duque de Caxias tem muitas histórias de violência relatadas em vários estudos e as vias férreas também é protagonista destas histórias de violência urbana.

Os participantes da pesquisa revelaram que as formas de travessia da linha férrea utilizadas por eles são: passagens de nível: 42\%; viadutos: 10\%; passarelas: $71 \%$; 
passagem subterrâneas: 4\%; passagem clandestinas: $11 \%$ e outros $11 \%$ revelaram que não há muros entre as ruas/casas e a linha férrea, sendo assim a travessia é livre, ou seja, atravessa a linha sem nenhuma barreira.

Há passagens de nível e passagens de pedestres clandestinas, feitas pelos moradores, cuja finalidade é constituir uma forma mais rápida de atravessar a via férrea. Estes tipos de passagens, em geral, são feitos por "meliantes", e, neste sentido, observa-se que a violência é um dos agravantes relacionados a via férrea, pois estes utilizam a via para consumir drogas e cometer delitos como roubos e assaltos.

As fronteiras criadas pelas vias férreas, observadas pela paisagem urbana por vezes diferenciadas nos dois lados da via, "representam, na maioria das vezes, barreiras" (JACOBS, 2011). Por este motivo, algumas são depredadas, justamente por não serem observadas pela população como uma forma de manter a população em segurança ao atravessar a linha férrea.

As passagens clandestinas são formas mais rápidas e com menor distância para realizar a travessia da linha. A questão da insegurança, em geral, é pormenorizada pelas pessoas, seja porque a passagem regular está distante para um determinado grupo, ou, de certa forma, por um comportamento que ignora os perigos em decorrência da utilização desse tipo de passagem. Jacobs (2011), que traz exemplos de lugares com fronteiras, nos Estados Unidos da América, salienta que estes lugares, em geral, são abandonados, e, portanto, são desertos, pois nenhum empreendimento quer se estabelecer em lugares que restringem a circulação de pessoas. Mas em se tratando de lugares periféricos, como no município de Duque de Caxias, as pessoas continuam construindo residências e utilizando de um "jeitinho" para poderem ultrapassar estas barreiras e circularem de um lado ao outro da via férrea.

\section{Conclusões}

A mobilidade urbana é fundamentalmente analisada pelo viés capitalista, onde a prestação de serviços sai do direito do cidadão para o direito do capital. A Baixada Fluminense foi palco de grandes transformações geográficas resultando em 13 municípios, formada com pessoas de origens vindas de todos os lugares do Brasil e do mundo, foi explorada para o bem o capital. A população passou e passa por problemas hegemônicos, de violência e ainda por problemas relacionados ao direito de ir e vir, relacionados as zonas de fronteiras criadas pelas ferrovias. Do ponto de vista das políticas públicas urbanas, conforme demonstrado brevemente neste trabalho, apresenta resultados ínfimos em relação aos problemas de segurança e estrutura ao longo da linha férrea.

Uma questão fundamental em relação à realidade urbana no entorno da ferrovia que corta a cidade caxiense diz respeito à necessidade de planejamento urbano atender a extensão ao longo da ferrovia, que está desprovida de uma acessibilidade que seja capaz de atender a população com qualidade. Dessa forma, do ponto de vista da mobilidade 
urbana, o planejamento deve contribuir para que a ferrovia seja vista como algo que vem a somar para as pessoas moram próximas a ela. Jacobs (2011), vê as regiões portuárias (por exemplo) como zonas de fronteiras, assim como as ferrovias, mas havendo uma transformação na qual a população local possa fazer parte do processo, através de pesquisas de opinião e/ou demais instrumentos que salientam o desejo e a necessidade daqueles que habitam a região que se quer planejar urbanisticamente.

\section{Referências}

HARVEY, D. Cidades rebeldes: do direito à cidade à revolução urbana. São Paulo: Martins Fontes, 2014.

JACOBS, J. Morte e vida de grandes cidades - $3^{\text {a }}$. Ed. São Paulo: WMF Martins Fontes, 2011.

LACERDA, S. Uma passagem pela Caxias dos anos 60: fragmentos de memória e registros diversos. Duque de Caxias: ed. do autor, 2001.

LACERDA, S. J. S.; VILlAR, L. S.; SOUZA, M. S.A Emancipação Política do Município de Duque de Caxias: uma tentativa de compreensão. Textos sobre a História de Duque de Caxias e da Baixada Fluminense. Órgão de divulgação conjunta: Instituto Histórico Vereador Thomé Siqueira Barreto / Câmara Municipal de Duque de Caxias e Associação dos Amigos do Instituto Histórico. Revista Pilares da História Ano II, $n^{\circ}$ 03, dezembro de 2003. 101p.

LEVEBVRE, H. O direito à cidade. Trad. Rubens Eduardo Frias. São Paulo: Centauro, 2001.

RODRIGUEZ, H. S. A formação das estradas de ferro no Rio de Janeiro: o resgate da sua memória. Memória do Trem, 2004.

SOUZA, M. S. Escavando o passado da cidade: história política da Cidade de Duque de Caxias. Duque de Caxias: APPH-CLIO, 2014.

VASCONCELLOS, E. A.Mobilidade urbana: o que você precisa saber. São Paulo: Companhia das Letras, 2013. 